\title{
A Lego-based Outreach Module Aimed at Promoting Advanced Manufactur- ing Careers to K-12 Students in the United States
}

\section{Mr. Christopher Andrew Almodovar, Rensselaer Polytechnic Institute}

Christopher Almodovar is a mechanical engineering student of Rensselaer Polytechnic Institute's class of 2013.

\section{Mr. Kyle Mattson, Timken}

Kyle Mattson graduated from Rensselaer Polytechnic Institute in 2011 with a Bachelor's of Science in Mechanical Engineering and again in 2012 with a Master's of Engineering in Mechanical Engineering. Both degrees were focused in manufacturing. He started with Timken, a bearing and power transmission company, in June as a participant in their Operations Development program.

\section{Mr. Evan Karl Day, Rensselaer Polytechnic Institute \\ Mr. Sean McKibben, Rensselaer Polytechnic Institute \\ Richard Yoo \\ Prof. Johnson Samuel, Rensselaer Polytechnic Institute}

Dr. Samuel is currently working as an assistant professor in the Mechanical, Aerospace and Nuclear Engineering department at Rensselaer Polytechnic Institute (RPI) in NY where he spearheads research and education activities in the areas of advanced manufacturing and material design. He completed his Ph.D. from the University of Illinois at Urbana Champaign in 2009 under the guidance of Prof. Richard E. DeVor and Prof. Shiv G. Kapoor. His research interests lie at the confluence of advanced material systems and micro/nano-scale manufacturing processes. He is also deeply passionate about promoting advanced manufacturing education and careers to K-12 students in the U.S.

\section{Mr. David E Silverman}




\section{A Lego-based Outreach Module Aimed at Promoting Advanced Manufacturing Careers to K-12 Students in the United States (Work in Progress)}

\section{Introduction}

Advanced manufacturing has recently taken center-stage in the United States (US) with the federal government rolling out major programs that are aimed at promoting US-based manufacturing. While these initiatives point towards a possible resurgence of the high-value manufacturing sector in the US, achieving the above goal is currently hampered by two major roadblocks. First, there is a serious shortage of trained manufacturing professionals in the US, and second, there is a poor perception of manufacturing jobs amongst the youth in the US that has affected recruitment and retention of professionals in this field. In the light of the current circumstances, there is a serious national need to recruit K-12 students to pursue manufacturingcentered education fields and careers.

There have been several outreach initiatives designed to generate K-12 student interest in manufacturing engineering ${ }^{[1-4]}$. Devine and Zimmerman developed a low cost industrial robot activity that targets second grade students. The goal of their activity was to change the perception that robots are not just androids of the future but that they have practical uses in industry today ${ }^{[1]}$. Chen et al. ${ }^{[2]}$ developed an outreach program with the Girl Scouts of America that included several unique workshops that covered topics such as materials, computer-aided design, virtual and rapid prototyping, and manufacturing processes. These workshops highlighted the key concepts of manufacturing engineering through demonstrations and activities. Jack ${ }^{[3]}$ wrote about an initiative to increase the number of students seeking manufacturing engineering education. He suggests doing this by streamlining the educational process to manufacturing engineering through agreements between secondary and higher education institutes, mentoring, and a "college-level launch-pad course". Coulter et al. [4] incorporated educational outreach into an undergraduate manufacturing course by inviting local high school students to work with the Lehigh University undergraduates during certain portions of the course ${ }^{[4]}$. While these outreach efforts are commendable, none of these programs target micro/nano-scale manufacturing education, which is an integral part of US-based manufacturing technologies in the $21^{\text {st }}$ century. Furthermore, most of the above activities required the K-12 students to visit the facilities of the organizers. A more effective approach would be one that brings micro/nano-scale manufacturing education into the K-12 classrooms. This would make the outreach module to be customizable for classrooms across the US thereby ensuring a nationwide impact.

This paper presents the details of a novel Lego $^{\mathrm{TM}}$-based micro/nano-scale manufacturing education outreach module that has been developed to be customizable for specific K-12 classrooms. The content of the module is structured around additive and subtractive manufacturing at the micro/nano-scale. The future additions to the module will involve the concept of "micro-factories" [5]. The remainder of this paper is organized as follows. Section 2 describes the overall design of the outreach module. Section 3 describes the candidate micro/nano-scale manufacturing technologies that are being used as the basis of developing this module. Section 4 describes the components of the module focusing on the interactive 
presentation and the design of the Lego ${ }^{\mathrm{TM}}$-based micro-scale machine tools (mMTs). It also presents some of the initial survey instruments that are being developed to assess the impact of the module. This is followed by Section 5 that presents the initial observations from the use of this module in classrooms and high-school outreach activities. Finally, Section 6 presents the conclusions that can be drawn from this work.

\section{Outreach Module Design}

The three main goals of the outreach module include: 1) Pedagogically-appropriate presentation of the current manufacturing workforce crisis and the need for trained manufacturing professionals in the United States; 2) Inspiring student interest in manufacturing engineering; and 3) Enable student learning by introducing additive and subtractive manufacturing concepts at the micro/nano-scale. These goals are achieved through a highly interactive 50 minute in-class activity that comprises of a presentation that promotes active learning and a hands-on demonstration of micro/nano-scale manufacturing techniques using Lego ${ }^{\text {TM }}$-based three-axis motion platforms.

Figure 1 presents the overall structure of the module. First, the participant's attitude and knowledge of manufacturing is assessed through the use of a pre-survey. After this information is recorded, the module begins by facilitating an in-class discussion aimed at identifying the current view of the students as it relates to manufacturing in the US. This discussion typically brings out the commonly held view that manufacturing implies "dirty jobs that do not involve much creativity" [6]. Once this issue has been brought to the forefront, a dynamic vision of micro/nano-scale manufacturing is presented using an interactive presentation that is then followed by a Lego ${ }^{\mathrm{TM}}$-based activity. The educational content of the presentation focusses on both additive and subtractive manufacturing technologies. The Lego ${ }^{\mathrm{TM}}$-based activities give a live simulation of the actual processes used by these technologies. Following this, a discussion and video are used to challenge the student's original view about manufacturing in the US. The activity concludes with an exit survey that is aimed at assessing the affective impact of the module.

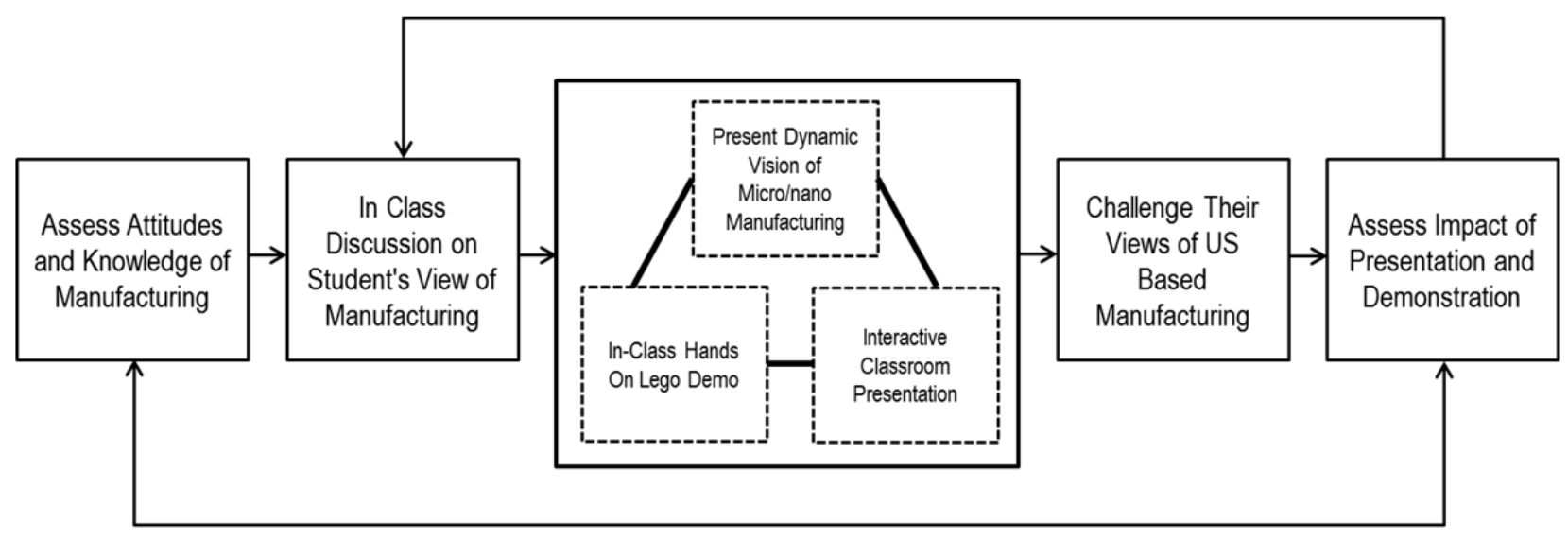

Figure 1: Outreach Module Flow Chart

The uniqueness of the module lies in its presentation and in the demonstration tools. The presentation is creative in its ability to convey the concepts of the micro/nano-scale and true 3D 
manufacturing at those scales. The demonstration tools are working models of micro-scale machine tools (mMTs) built primarily out of Lego ${ }^{\mathrm{TM}}$ units that are very attractive to students in the K-12 age bracket.

\section{Candidate Micro/Nano-scale Technologies}

The module primarily demonstrates the capabilities of two processes viz., printing-based additive manufacturing processes at the nano-scale and material removal processes (subtractive processes) at the micron/sub-micron-scale viz., micro-milling/drilling/turning ${ }^{[7]}$. In addition to these two processes, the module also demonstrates the concept of micro-scale machine tools (mMTs) that form the building blocks of the micro-factory concept ${ }^{[5]}$. This section briefly reviews each of these technologies.

\subsection{Printing-based Processes at the Nano-scale (Additive Manufacturing)}

The near-field electrohydrodynamic-jet (E-jet) printing process has recently gained significant interest within the manufacturing research community because of its ability to produce submicron-scale droplets using a wide variety of inks and substrates ${ }^{[8,9]}$. This process has emerged as a new tool for liquid-based additive manufacturing at the sub-micron-scale. It uses electric fields to create fluid-flows through micro-capillary nozzles to deliver ink onto the substrate in the form of a charged micro-jet. The resulting printed droplets are as small as $0.25-10 \mu \mathrm{m}$ in diameter. The inks used include a variety of functional organic and inorganic inks, as well as suspensions of solid objects.

Figure 2 depicts the schematic lay-out of the near-field E-jet printing set-up. The basic elements include an ink chamber, glass nozzle tip, substrate, and a precision three-axis positioning system. The controllable printing process parameters are the back pressure (pneumatic) applied to the ink chamber, the gap-height between the nozzle and substrate, and the applied voltage potential between the nozzle tip and substrate. In the first-generation process developed by Park et al. ${ }^{[8]}$, a constant D.C. voltage was applied between the nozzle and the substrate to create a constant electric field, which resulted in periodic droplet ejection from the nozzle onto the substrate surface. Use of a pulsating voltage technique was seen to result in printing speeds in the $1-2 \mathrm{KHz}$ range ${ }^{[9]}$ as compared to the low speeds of $1-5 \mathrm{~Hz}$ in the process developed by Park et al. ${ }^{[8]}$. The applied voltage and the motion stages can be controlled and coordinated to deposit arrays of droplets at desired locations.

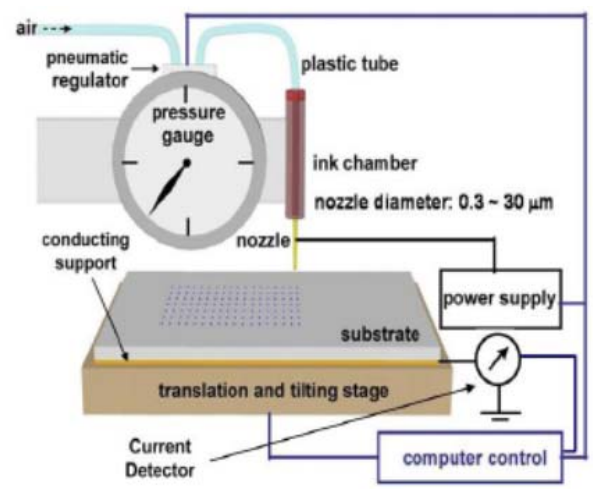

Figure 2: Near-field Electrohydrodynamic Jet-based Additive Manufacturing Process ${ }^{[8,9]}$ 


\subsection{Material Removal Processes at the Micro/Sub-micron-scales (Subtractive Manufacturing)}

This is a scaled-down version of the conventional macro-scale subtractive manufacturing processes such as milling, drilling, and turning. The tools used in this process vary from 20-500 $\mu \mathrm{m}$ in diameter. The small size of the tools necessitates the use of high speed spindles in the 50,000-150,000 RPM range. It also necessitates smaller depths of cut and feed rates (i.e., chipload values) on the tool and atomized delivery of the cutting fluid, so as to prevent tool breakage $[10,11]$. Figure 3 shows a typical micro-scale machine tool (mMT) and spindle set-up along with some of the unique geometries that are feasible with this process.

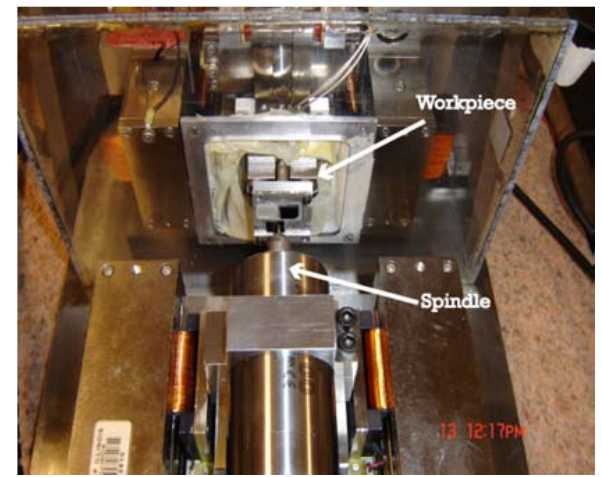

(a) Three-axis micro-scale machine tool (mMT)

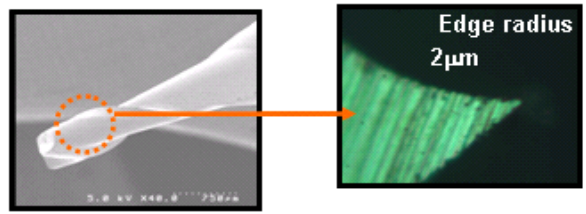

(b) A 100 micron-milling tool showing an edge radius of $2 \mu \mathrm{m}$
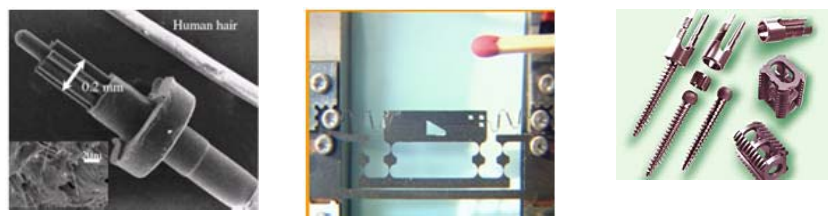

(c) Micro-parts made using micro-milling ${ }^{[5]}$

Figure 3: Micro-milling Capabilities

\subsection{Micro-Factory Concept}

With the design and build of table-top micro-scale machine tools (mMTs) seen in Figure 3, the notion of a portable factory has started to gather momentum within the manufacturing research community ${ }^{[5]}$. Figure 4 below shows two such portable micro-factory units that have been developed in Germany and Japan. These units are portable bench-top factories that have 3-4 mMTs connected in-tandem to operate in a factory setting. This technology is critical in enabling "point-of-need manufacturing", i.e., taking manufacturing to the end-user to enable mass customization.

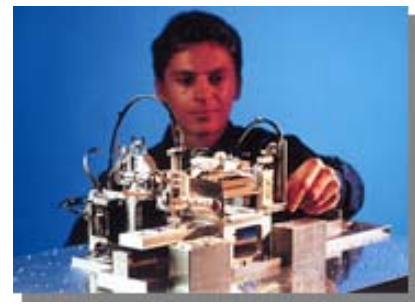

IPA Stuttgart - Germany Desktop Microfactory

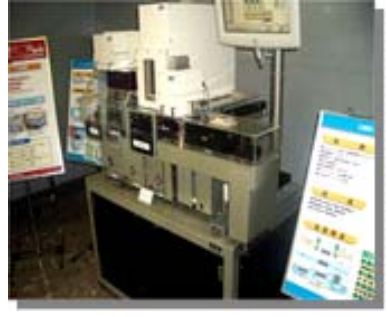

SANKYO SEIKI - Japan Desktop Factory Units

Figure 4: Micro-factory Concepts ${ }^{[5]}$ 


\section{Components of the Module}

This section provides an overview of the three building blocks of the outreach module, viz., 1) the interactive multi-media presentation; 2) the design of the Lego ${ }^{\mathrm{TM}}$-based micro-scale machine tools (mMTs); and 3 ) the survey instruments used.

\subsection{Interactive Multi-media Presentation}

Students in the K-12 age group vary considerably in their exposure to technical sciences, specifically manufacturing, and in some cases may have never been exposed to the field of micro/nano manufacturing. For this reason, it was important to be creative in both the content and the presentation of the educational content. It was decided that the module would first be designed to target high-school students and once it is proven at that level, specific content would then be developed for lower aged students. Furthermore, since the aim is to keep the students upbeat and excited about what they are learning, the presentation was built around the use of technology, hands-on activities, and active participation. Rather than using the conventional powerpoint-based presentation, the authors used Prezi ${ }^{\mathrm{TM}}$, which is a "cloud-based" story-telling tool for exploring and sharing ideas on a virtual canvas. Prezi ${ }^{\mathrm{TM}}$ also allows the use of videos, images, diagrams and other forms of auditory and visual stimuli.

Figure 5 shows the opening image of the presentation and a creatively designed graphic used in the program. The presentation begins on this slide by fielding comments from students on their interpretations and impressions of manufacturing. As expected, a majority of students were seen to believe that manufacturing jobs are often dirty and laborious, with the majority of it taking place overseas away from the United States. The presentation intentionally begins with these questions to contrast their feelings before and after the presentation. In order to record these views and feelings in a more concrete manner, a survey is then distributed.

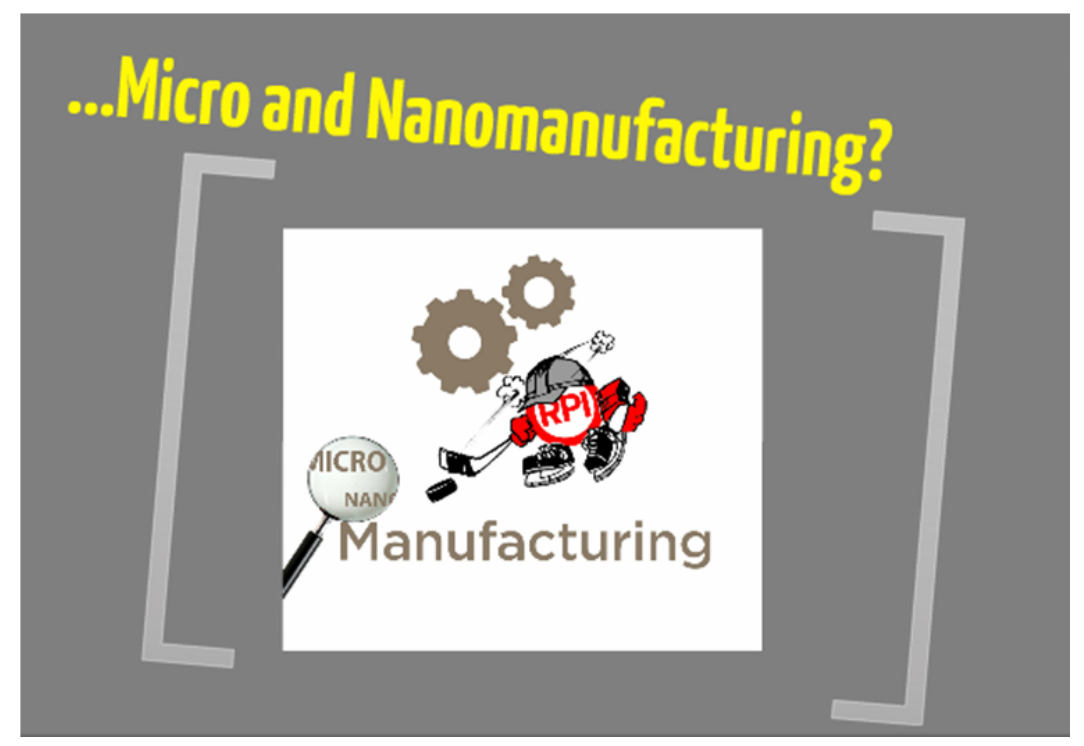

Figure 5: Opening Graphic Used in Interactive Prezi ${ }^{\mathrm{TM}}$ Presentation 
The conversation then turns to the topic of micro/nano-scale manufacturing. The field of micro/nano-scale manufacturing is presented in a fashion that will appeal to this generation and will stir excitement about pursuing a job in related industries. Products and processes familiar to the students are used to convey the idea that their day-to-day lives are affected by these manufacturing concepts. Figure 6 shows the "Micro and nano-manufacturing tree" used in the presentation to highlight the interplay between products and processes. As seen in the Figure 6, products that are highlighted include iPods, LED lights, micro-tools/dental spindles and microrobots. The additive and subtractive manufacturing processes used to make these parts are also highlighted.

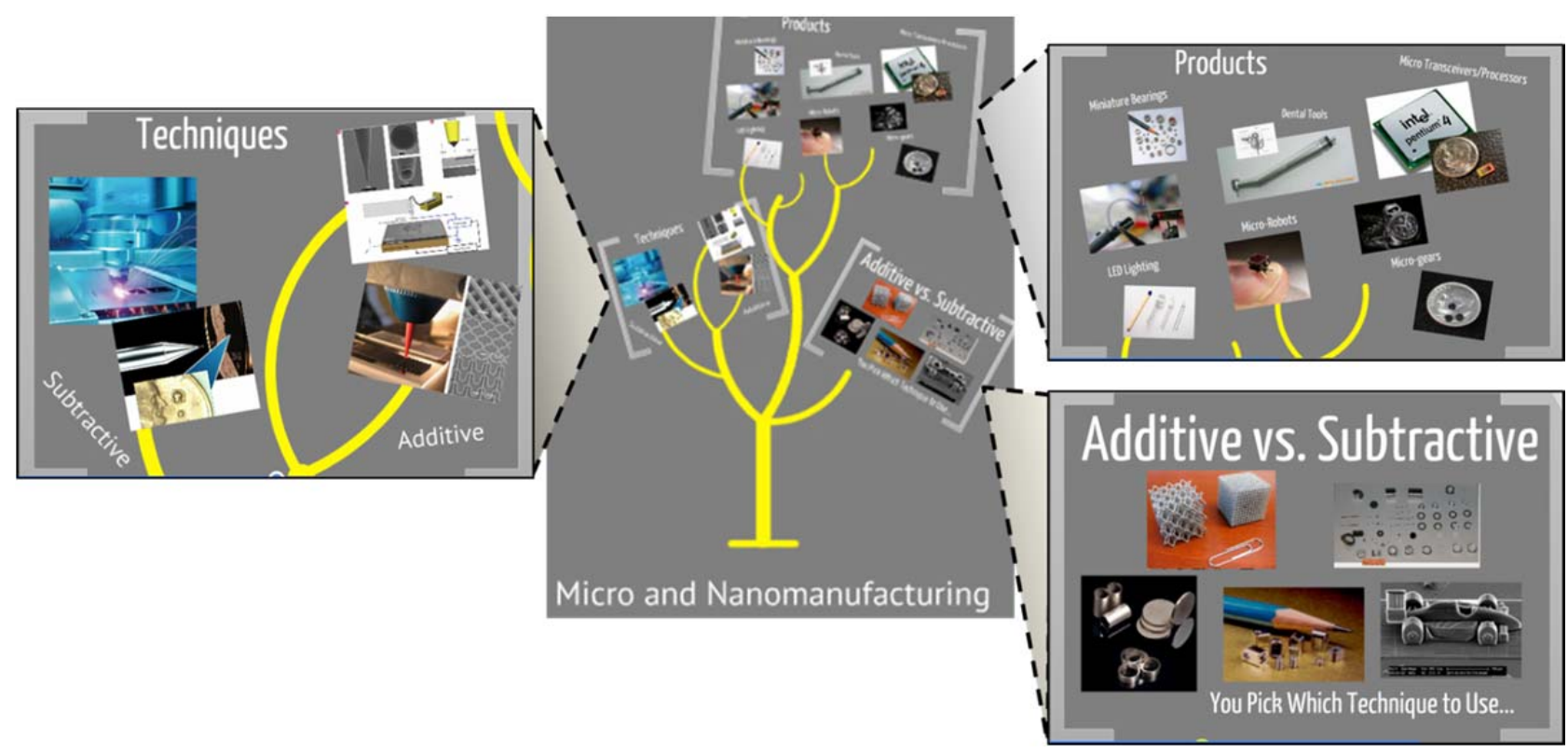

Figure 6: The Micro and Nano-manufacturing Tree

Once the connection has been established between the micro/nano-scale manufacturing technologies and the day-to-day lives of the students, an attempt is made to "wow" the audience by introducing the almost incomprehensible nature of the size-scales involved in these manufacturing technologies. The presentation does this by comparing the micro/nano-scale manufactured objects to those that the students can relate to in terms of perceived size-scales; for example a piece of hair, red blood cells and other such extremely small objects. Figure 7 shows the slide used to display this scaling concept. By placing the micro/nano-scale products next to the ruler, the audience is able to compare two items manufactured at entirely different scales. The presentation is designed in such a way that pictures can zoom in and out, to help the audience understand the magnitude of this scale fully. The Prezi ${ }^{\mathrm{TM}}$ allows the presenters to zoom in as shown in the callouts to the right of the slide. Shown are a strand of hair, red blood cells, and other micro-manufactured figures. 


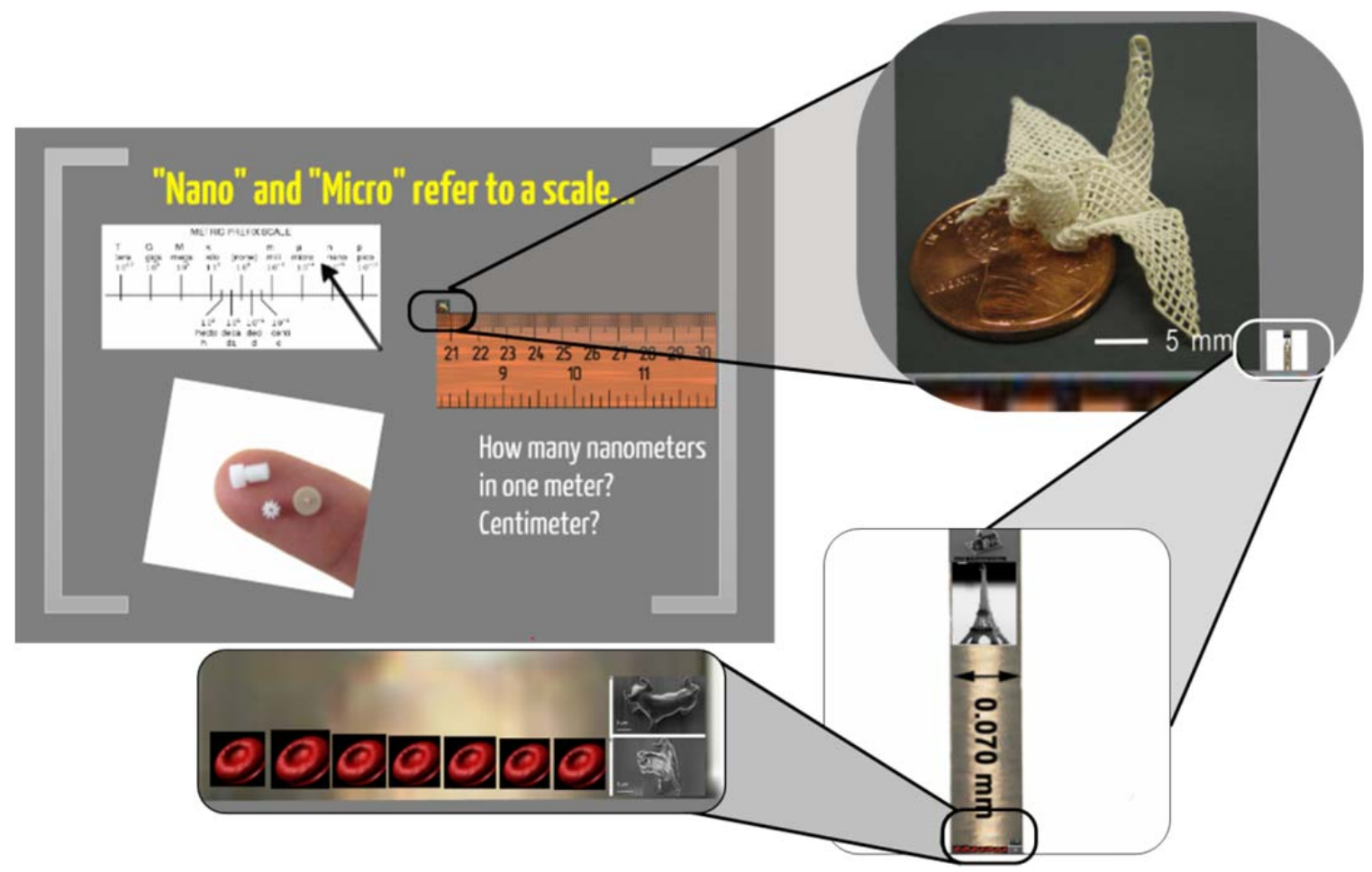

Figure 7: Presentation Slide Demonstrating the Scale of Micro/nano Products

Now that the size-scales have been grasped by the students, the presentation introduces the technical content as it relates to additive and subtractive manufacturing. In order for students to recognize the difference between these two very important techniques, concrete examples of each technique are presented at both the macro and micro scales. The Prezi ${ }^{\mathrm{TM}}$ presentation slide used to compare and contrast these techniques can be found in Figure 8. To ensure that students understand the difference between additive and subtractive processes, they participate in an interactive quiz where they are tested on whether or not they can determine if an object is produced using additive or subtractive techniques.

Once students understand these two manufacturing processes, the Lego ${ }^{\mathrm{TM}}$-based micro-scale machine tools (mMTs) are used to further reinforce these concepts. A significant portion of the module is set aside for students to interact with the Lego mMTs. Figure 9 shows the Prezi ${ }^{\mathrm{TM}}$ slide displayed during the Lego mMT demonstrations. The Lego mMTs can be programmed to manufacture various macro-scale 3D structures that can then be correlated to its micro/nanoscale counterpart using the pictures seen on the right hand side of Figure 9.

Finally, before wrapping up the presentation, a video is played which seeks to instill a sense of urgency for this generation of students in the United States to pursue the field of manufacturing. Questions and comments that students may have are then addressed. During the question-andanswer session, a similar survey as the one presented earlier is given to the audience. For further reference concerning the Prezi ${ }^{\mathrm{TM}}$ presentation, an online version of the presentation is provided at $\quad$ http://prezi.com/zsoceqaxgo $2 \mathrm{y} /$ manufacturing-outreach $/$ ?kw=view-zsoceqaxgo $2 \mathrm{y} \& \mathrm{rc}=\mathrm{ref}-$ 11796289. 


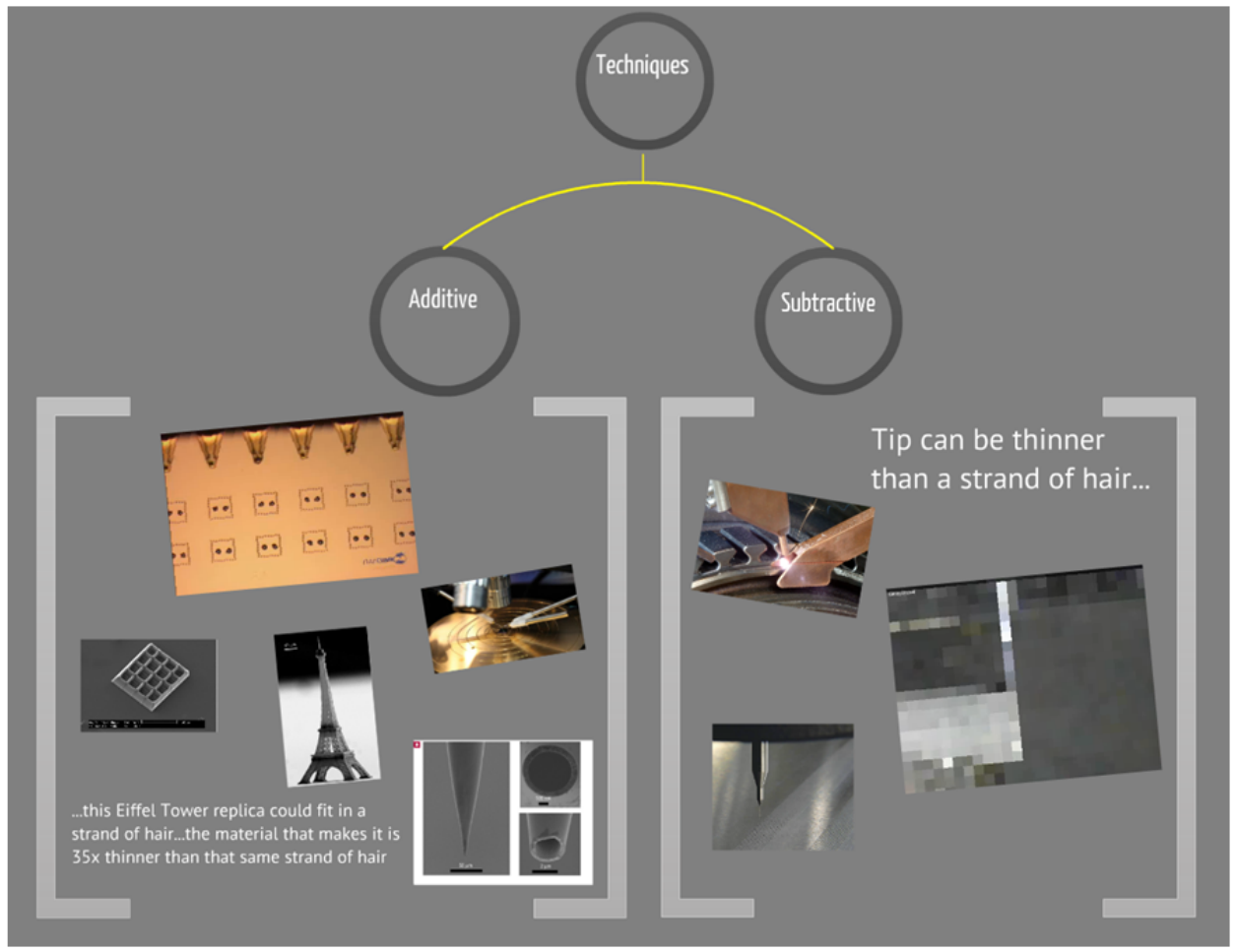

Figure 8: Comparison of Additive \& Subtractive Techniques

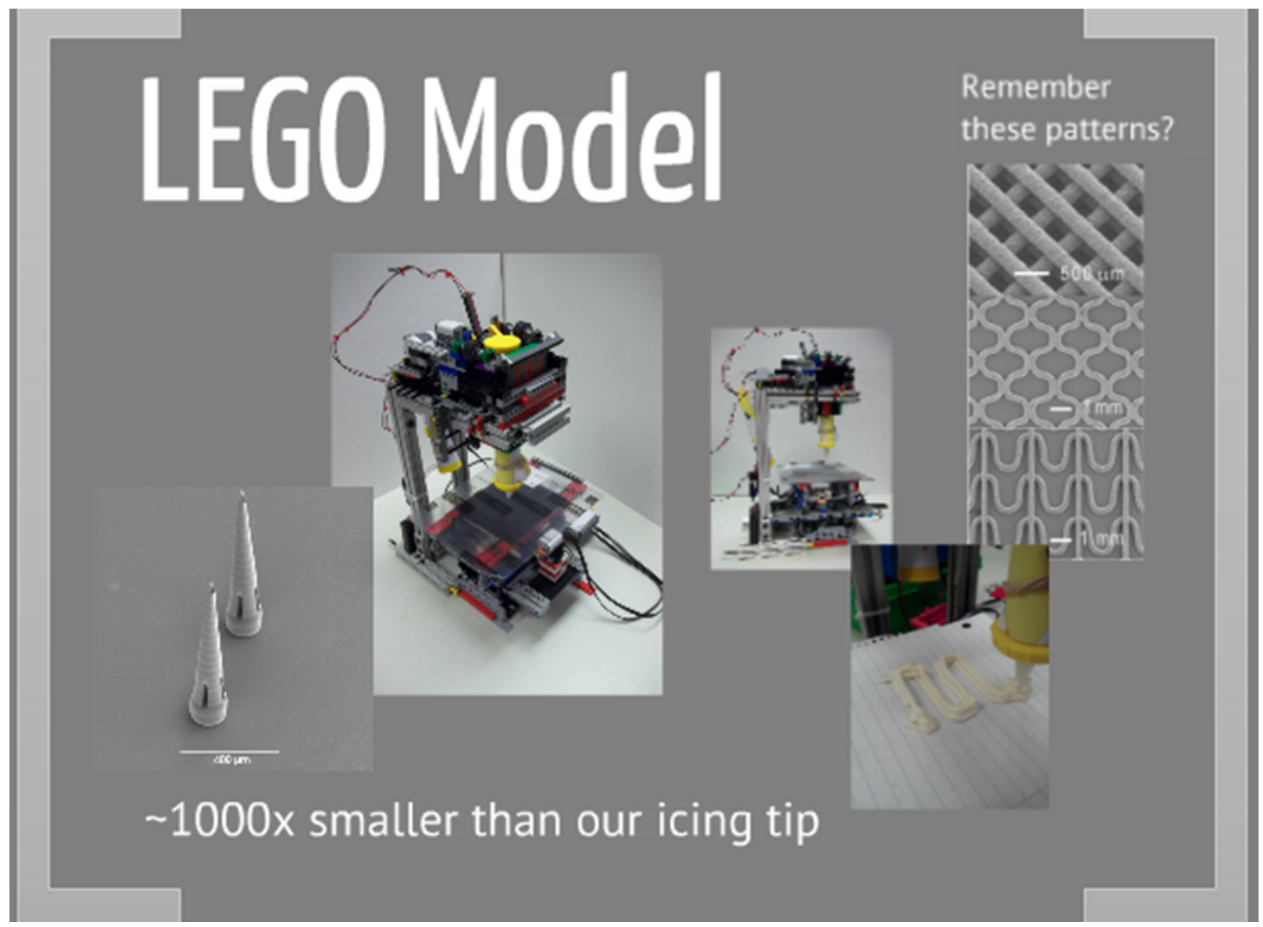

Figure 9: Lego Tool Activity

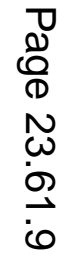




\subsection{Lego-based Micro-scale Machine Tools (mMTs)}

As part of this outreach effort, three Lego-based mMTs were designed to convey advanced manufacturing processes to the K-12 classroom. Although these mMTs are mounted with tools that demonstrate the process concepts at the macro-scale, these processes have clear parallels at the micro/nano-scale. The following sections describe the three mMTs designed as part of this module, viz., 1) the Additive Manufacturing mMT; 2) the Subtractive Manufacturing mMT; and 3 ) the Metrology mMT. In this section, the design and build of the additive manufacturing mMT is detailed, and only the designs of the subtractive machine and metrology unit are presented.

\subsubsection{Additive Manufacturing Micro-scale Machine Tool}

Figure 10 depicts the three-axis additive manufacturing mMT that was built for this module. The foot-print of this mMT is 13.5 " X 10.5 " X 17". The chosen design utilizes a table that moves in the $\mathrm{X}$ and $\mathrm{Y}$-axis (horizontal and lateral) and a tool carriage that moves in the Z-axis (vertical). An electronic cake icing extruder was used as the tool-head to demonstrate the additive manufacturing process done by technologies such as the nearfield E-jet ${ }^{[8,9]}$. Icing is a great way to demonstrate additive manufacturing as it is fluid enough to be extruded smoothly yet viscous enough to hold its shape. Furthermore, the students connect with it on a personal level because of its prevalent use at home.

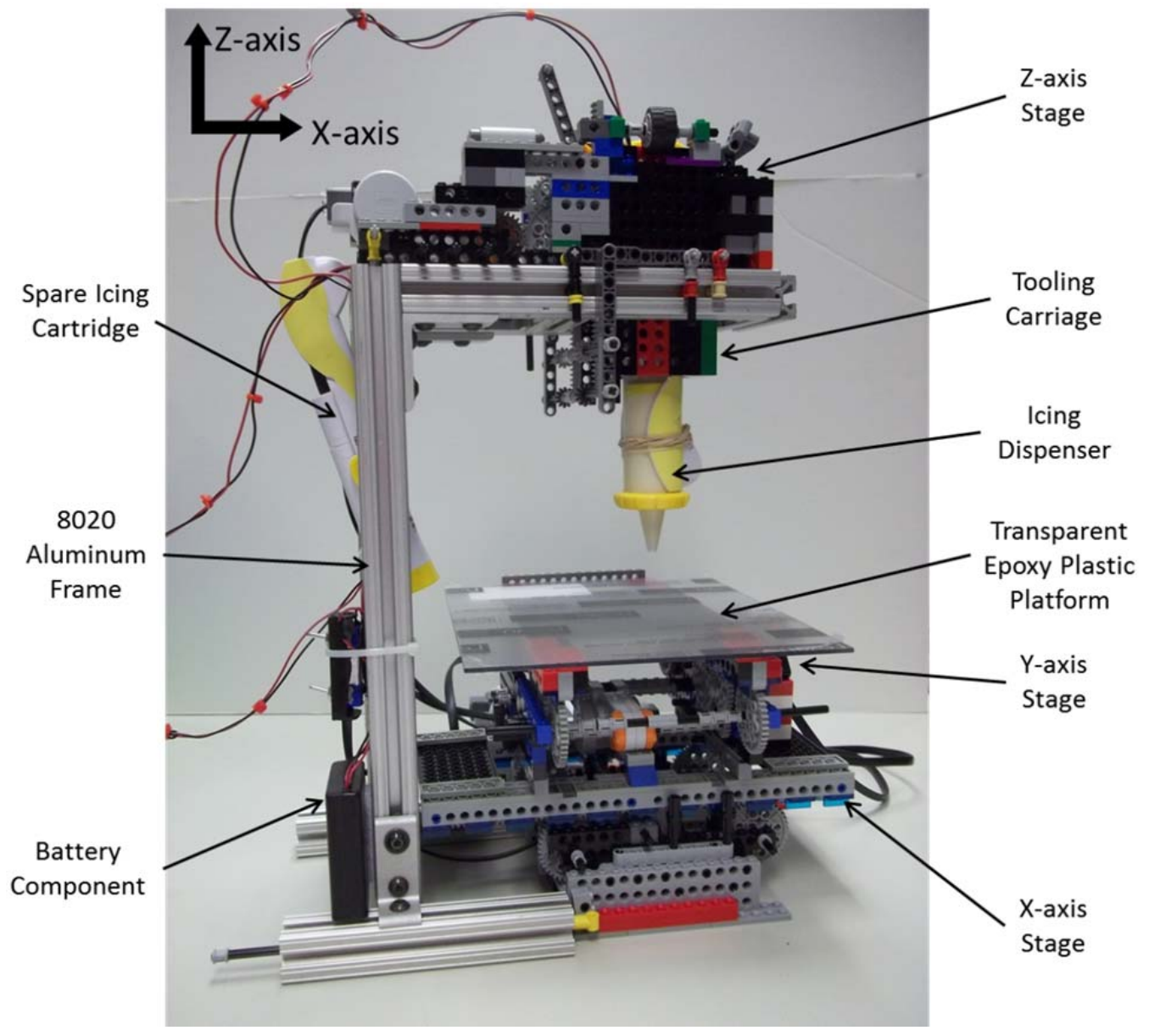

Figure 10: Additive Manufacturing Micro-scale Machine Tool 
The first component of the machine that was built was the XY table. A stacked configuration was chosen wherein the $\mathrm{Y}$-axis is mounted on top of the $\mathrm{X}$-axis stage. Given this configuration, the height of the stages had to be minimized to ensure stability of the substrate during movement. Furthermore, the tracks were also aligned with guards that helped guide the motion of the stage. These guards are visible as blue Lego pieces in Figure 11 that depicts the underside of the Y-axis stage.

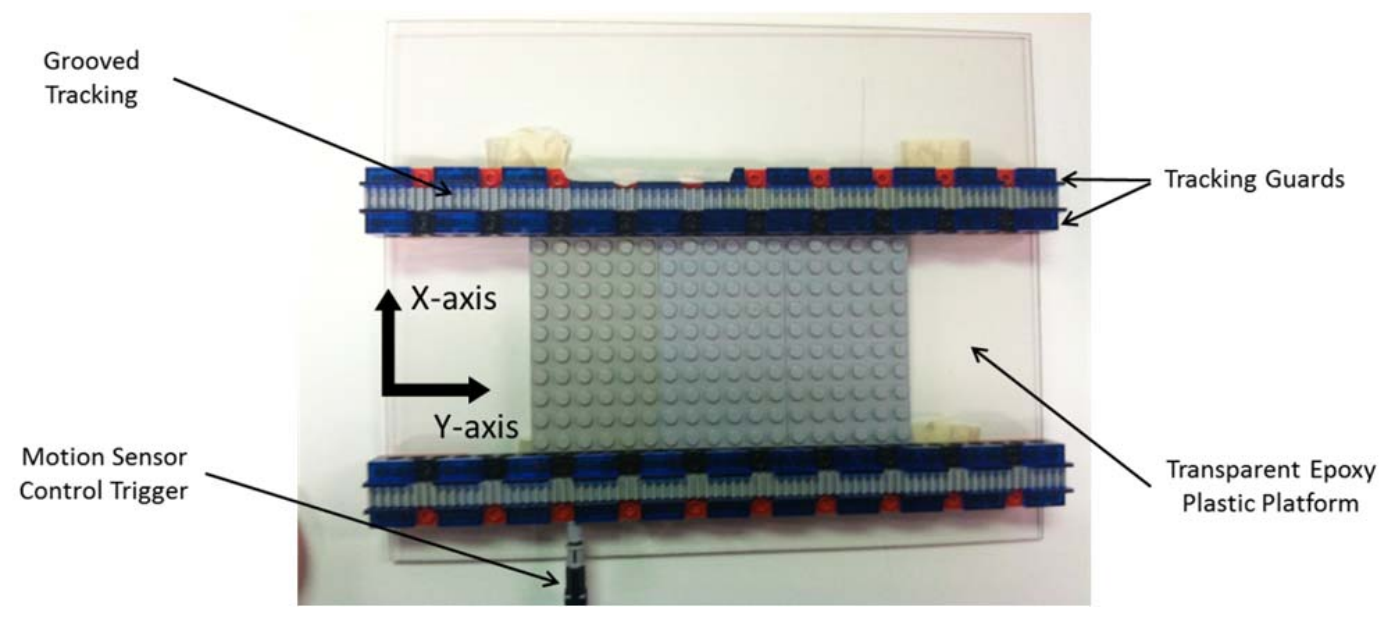

Figure 11: Y-axis Stage (Underside exposing tracking guards)

The next component built was the Z-axis frame which was made of 8020 Aluminum (Figure 12). It is a standard $\mathrm{C}$-shape frame designed to hold the icing extruder and movable parts of the Zaxis without impeding the motion of the $\mathrm{X}$ and $\mathrm{Y}$-axis table. In order to attach the $\mathrm{Z}$-axis tooling carriage (shown in Figure 13), Lego pieces were fit into the cavity that was designed specially for the tool head. Then the rack and pinion type gear system was added to the aluminum support to enable the motion of the tooling carriage (Figure 13).

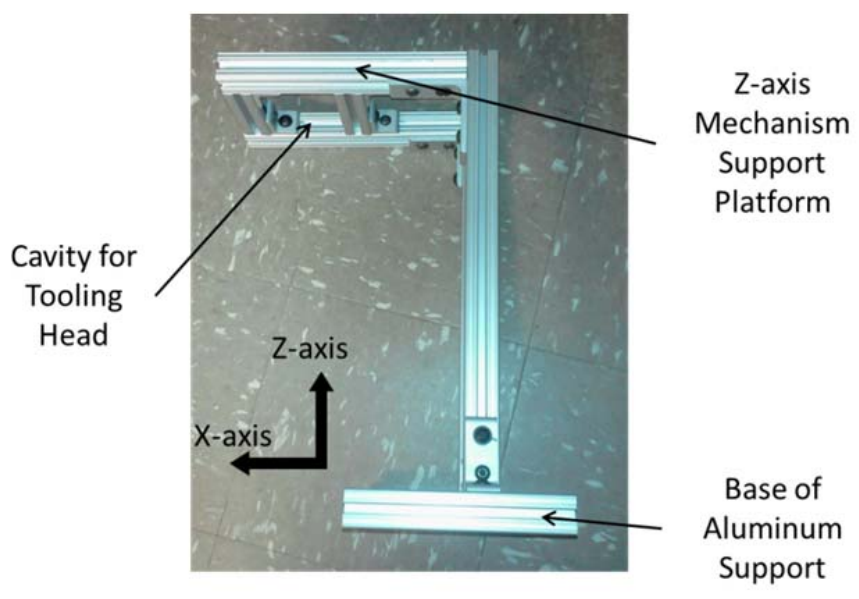

Figure 12: C-shaped Aluminum Frame Designed for the Additive Manufacturing mMT 
The purpose of the tooling carriage (Figure 13a) is to hold the icing dispenser (Figure 13b) and to translate the motion of the gears in a vertical direction. The tracks on the edges of the carriage align with the gears located in the Z-axis component.

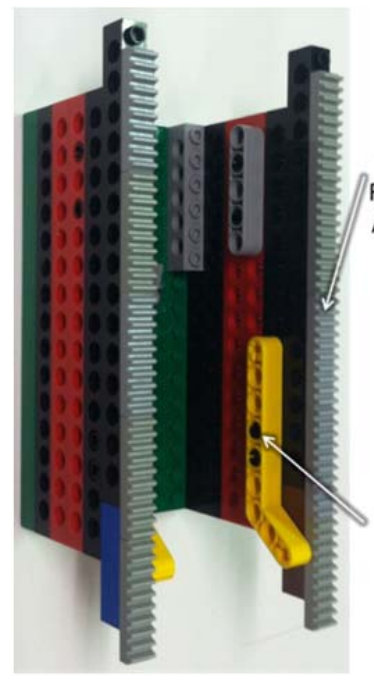

(a)

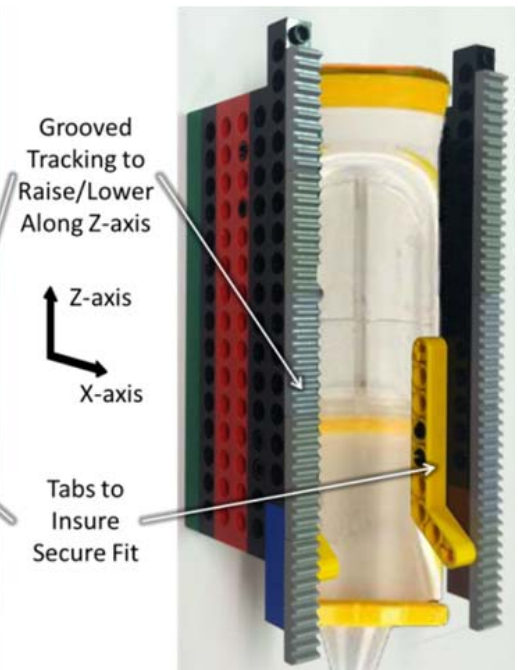

(b)

Figure 13: Z-axis Tooling Carriage

The icing dispenser, which was loaded into the tooling carriage, was wired to a switch and battery holder (Figure 14) in a series loop. By removing the battery holder from the icing dispenser and wiring the dispenser to an exterior battery holder, the weight of the dispenser was reduced. Then the components and wires were secured to the Z-axis frame to allow easy access to the switch and batteries.

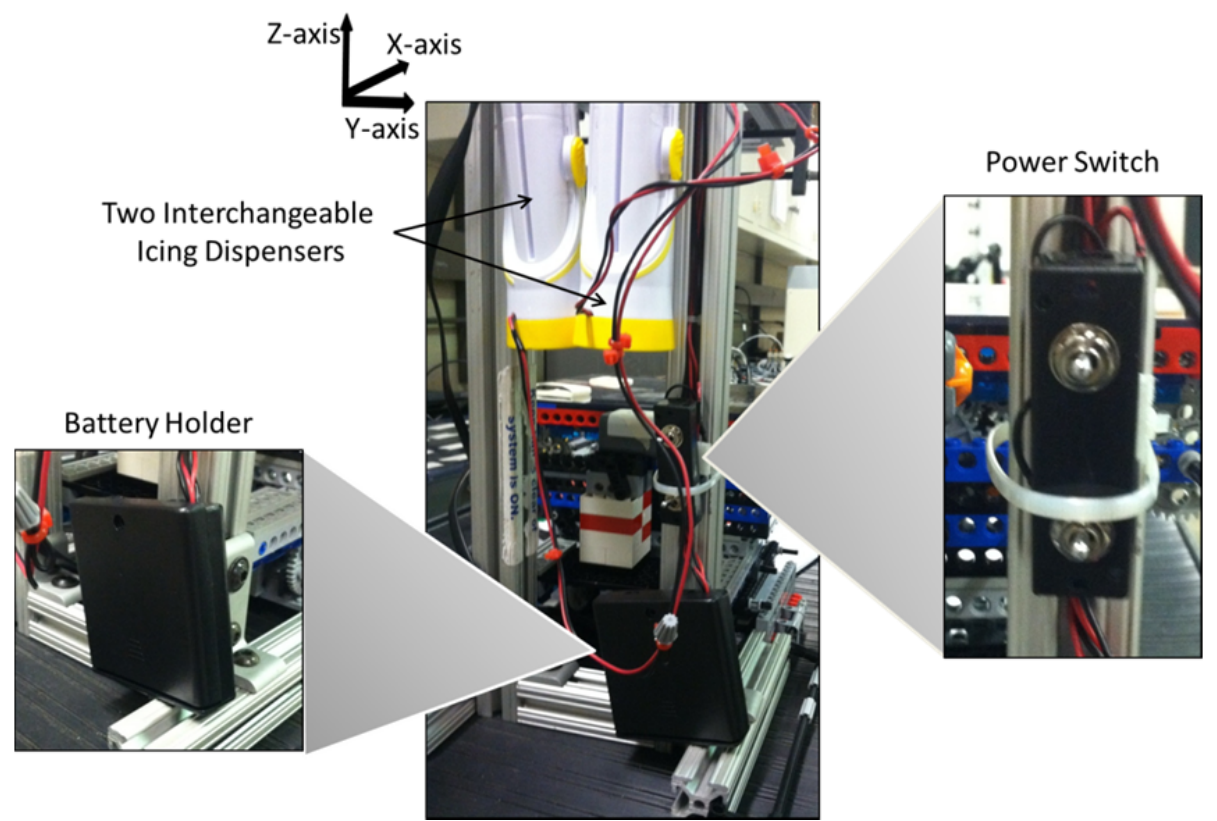

Figure 14: Battery Holder and Switch Mounting 
The control of the additive manufacturing mMT was achieved through the use of the Lego Mindstorms NXT controller. ROBOTC was used as the programming language for the controller. A program was then written for the icing dispenser to build a layer-by-layer pattern that resembled a nano/micro-scale structure. The directional touch sensors (Figure 15) were used to limit the travel of the XY stage and to zero the position of each motor. The Lego NXT motors use an encoder that has a tendency to drift after repetition if not reset.

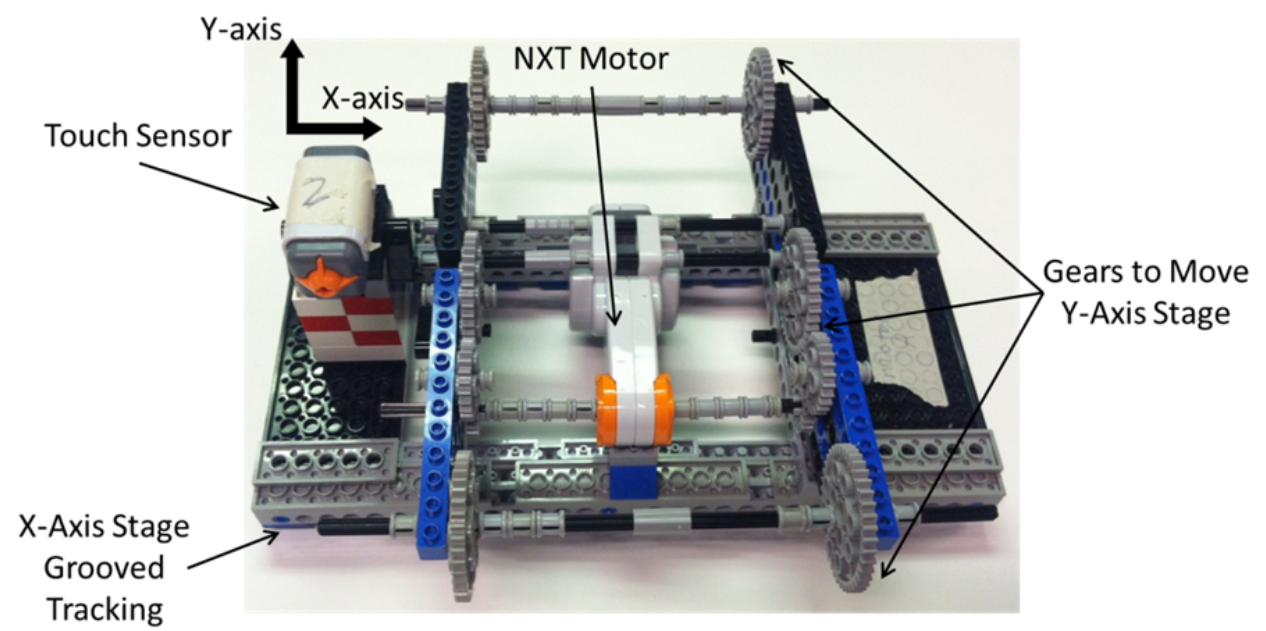

Figure 15: X-axis Stage Track with Y-axis Touch Sensor Mounted

The icing extrudes in the lattice pattern in Figure 16a. Figure $16 \mathrm{~b}^{[12]}$ is a similar pattern used for bone grafting at the micro-scale. By comparing these two similar structures the Lego ${ }^{\mathrm{TM}}$-based machining tool clearly draws the correlation between macro and micro manufacturing processes. Improvement of the ROBOTC code is under development. The goal of the update is to implement a system that can take user input and print it out of icing. The machine in action can be viewed at the following web address:

http://www.youtube.com/watch?v=GN3Le501XOk\&feature=g-like

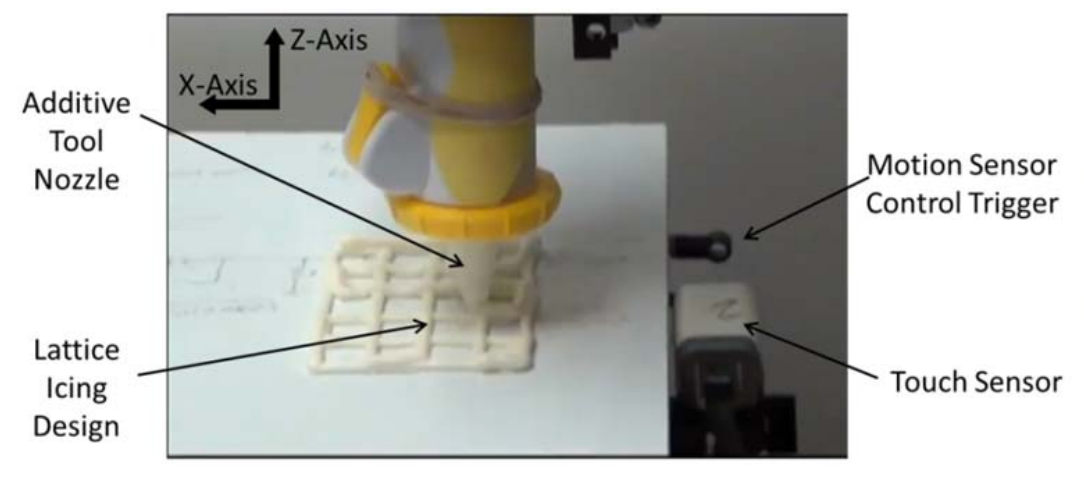

(a)

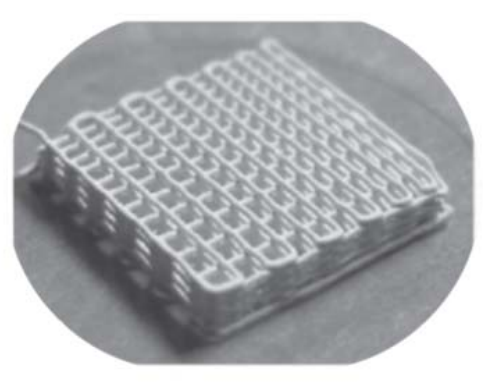

(b)

Figure 16: Additive Manufacturing Tools Demonstration Pattern 


\subsubsection{Subtractive Manufacturing Micro-scale Machine Tool}

For the design of the Subtractive Manufacturing mMT, a gantry configuration was selected because in addition to its flexibility and relevance to micro/nano-scale manufacturing, this configuration also provides the students to see another machine tool design configuration that is different from the $\mathrm{C}$-section used for the additive manufacturing $\mathrm{mMT}$.

Figure 17 depicts the overall design of the mMT. The footprint of the test-bed is 12 " X 14 " and is 7" high. As seen in the figure, the XY stage that carries the tooling head is mounted on top of the vertical platform constructed out of 8020 aluminum beams. This is done because the Lego ${ }^{\mathrm{TM}}$ pieces were determined to be unsuitable to support the load of the various $\mathrm{Lego}^{\mathrm{TM}}$ motors and non-Lego ${ }^{\mathrm{TM}}$ components moving in the XY plane. The top of the aluminum beams are lined with Lego ${ }^{\mathrm{TM}}$ rack gears to help guide the stage in the $\mathrm{Y}$-direction. The motor controlling the $\mathrm{Y}$ axis displacement is located in the back left of the frame and operates by reeling in the $\mathrm{X}$-axis stage with a set of connected rack gears. The $\mathrm{X}$-axis stage consists of a pair of parallel rack gears, a vertically mounted motor and the tooling carriage. To move the tooling head in the XY plane, the vertically mounted motor spins its attached gears to move along the parallel rack gears.

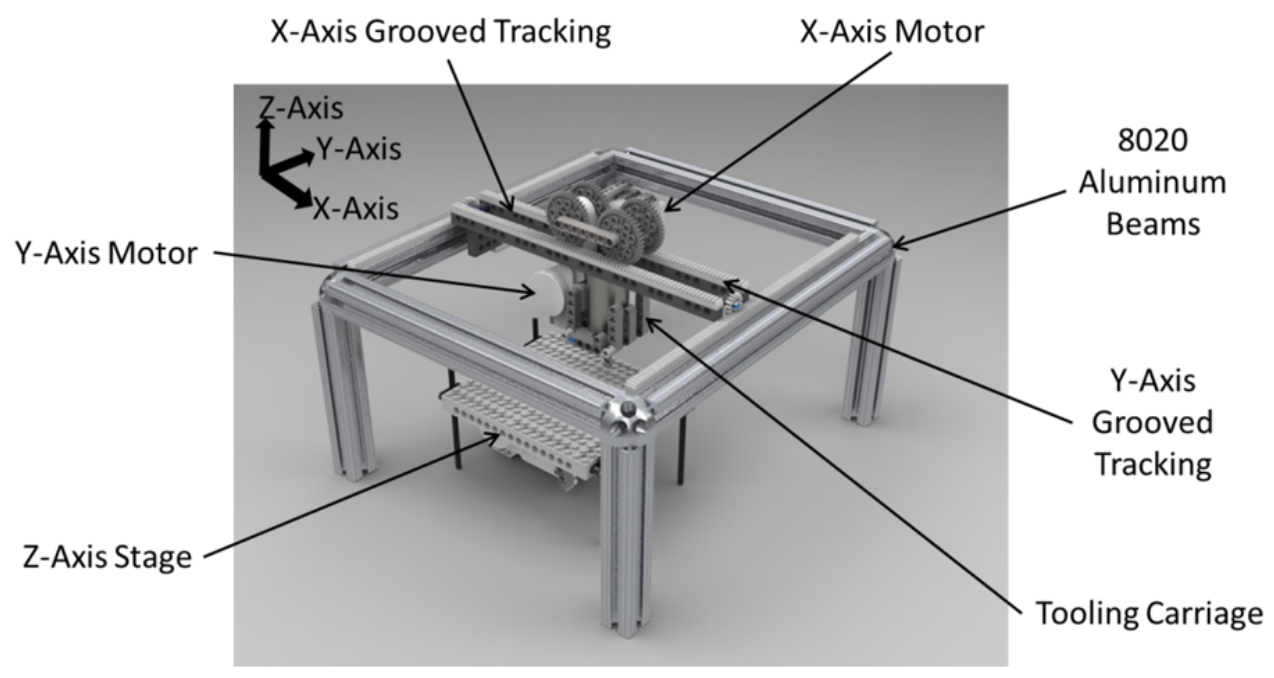

Figure 17: Gantry Design for Subtractive Manufacturing mMTs

The Z-axis stage is kept independent of the $\mathrm{XY}$ plane motion in order to make switching the tooling heads simpler. Figure 18 details the Z-axis stage. It is comprised of the stage, a horizontally mounted Lego ${ }^{\mathrm{TM}}$ NXT motor, a set of 4-bar linkages, and guide rails. In order to change the height of the Z-axis stage, the motor turns, forcing the bar linkages either up or down. To keep the motion vertical, four guide rails, one on each side of the stage, are implemented. 


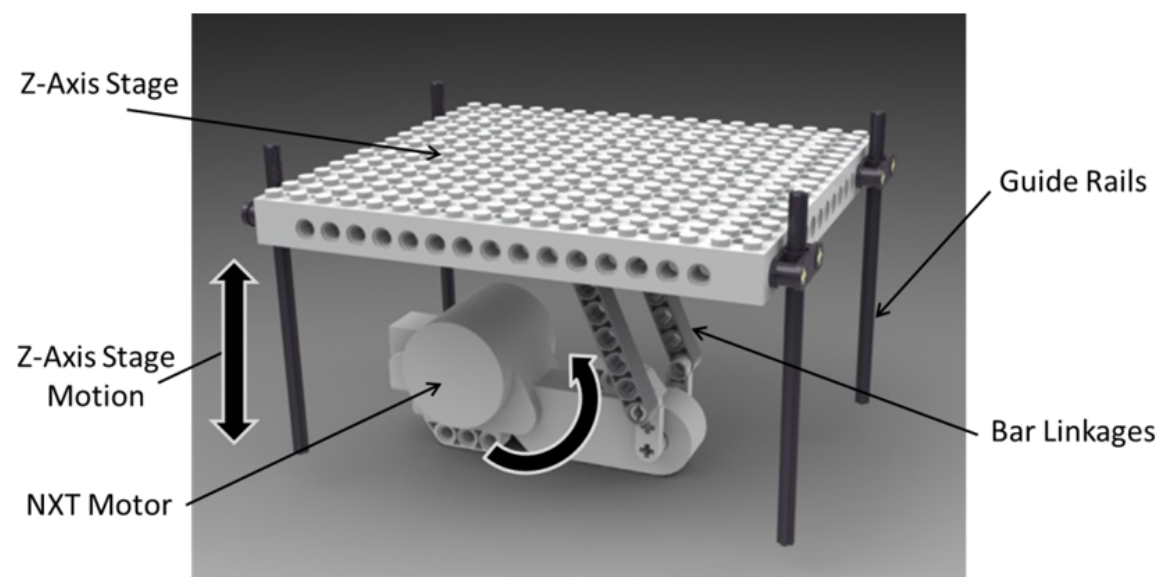

Figure 18: Z-Axis Stage

The tool chosen to demonstrate subtractive manufacturing was a $1 / 8$ " steel drill bit attached to a 7.4 volt brushless motor (Figure 19b). This will be mounted in the tooling carriage (Figure19a) in order to move in the X-Y plane. This will look and function similarly to machine tools and spindles used in the industry. Floral foam was selected as the substrate to be used for demonstrating the subtractive manufacturing process for its ease of machining and relative safety (no sharp chips will be produced). For the demonstration, students will input their initials into a graphical user interface (GUI) on a computer and the unit will mill them into the floral foam.

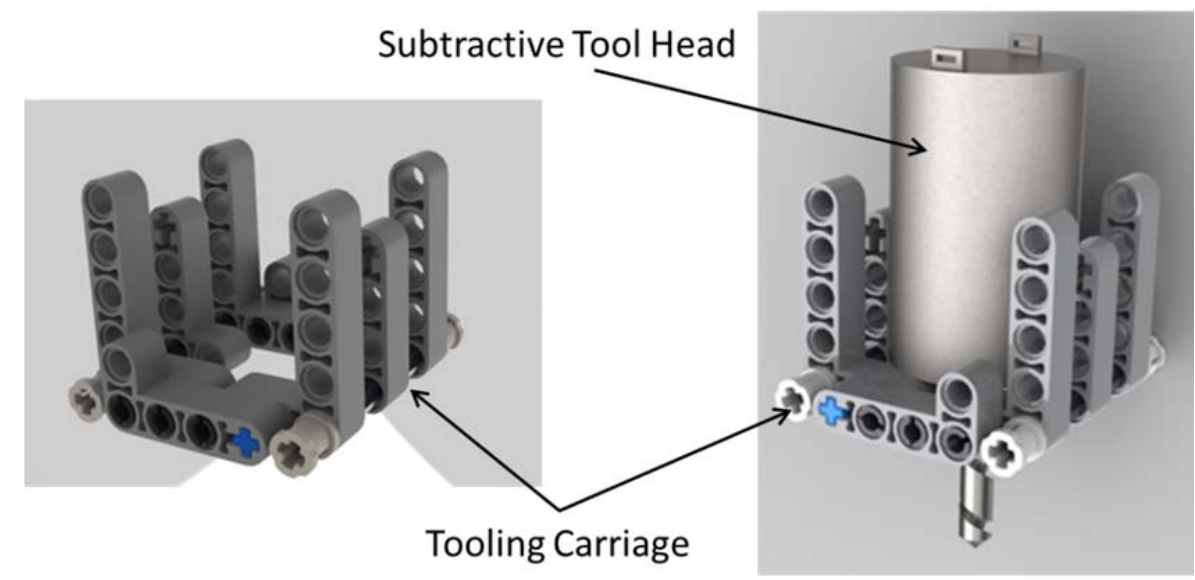

(a)

(b)

Figure 19: Brushless Motor in Machine Head Cradle

\subsubsection{Metrology Unit}

The metrology unit could be implemented with either the additive or the subtractive manufacturing mMT since it only involves mounting a different tool-head to either of the tooling carriages. Figure 20 shows the configuration when the metrology tool is mounted on the tooling carriage of the subtractive mMT. As shown in Figure 20b, it will be comprised of a flashlight (Figure 20a) with a light diffuser mounted over it. When the flashlight is turned on, it will scan a given sample and project a laser grid array (Figure 20c) which then pin-points variances in the 
surface height. By measuring changes in the location of the laser, a three dimensional representation of the sample is created.

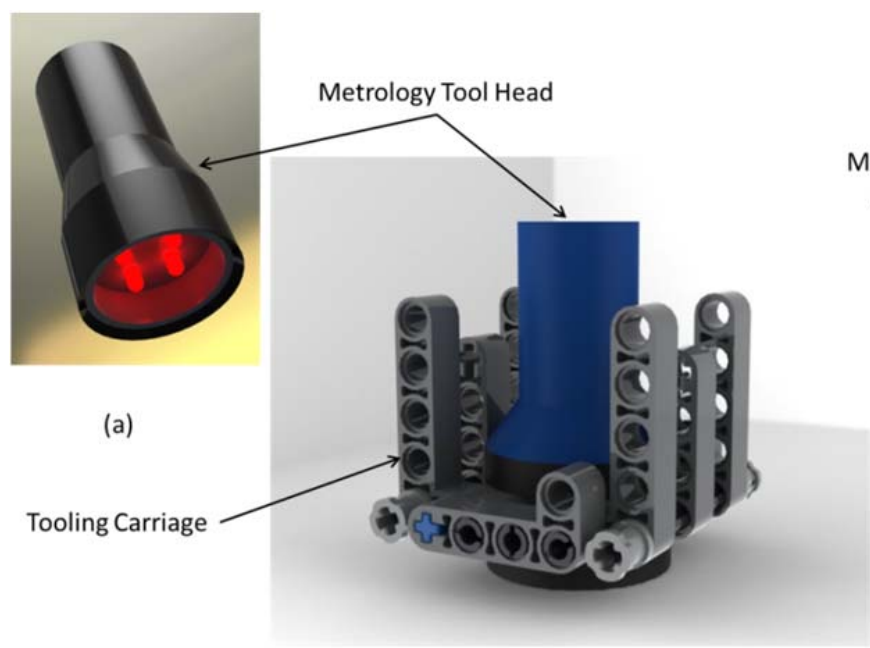

(b)

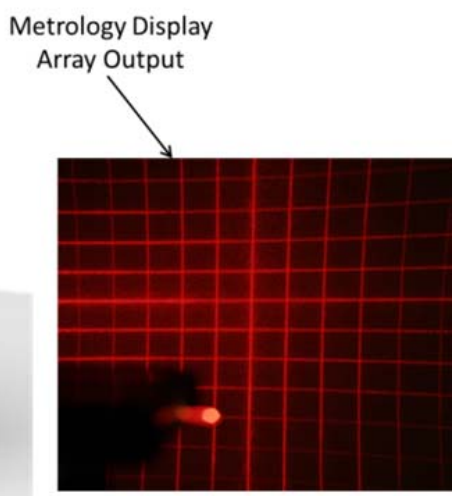

(c)

Figure 20: Metrology Unit in Machine Head Cradle

Since the Metrology unit is shared with the subtractive manufacturing unit, its motions will be identical. For the demonstration, a sample machined piece will be placed on the Z-axis stage. Then, the machine head will move over it slowly, shining the light on the part, to simulate scanning. Once the scanning is completed a premade 3D image of the 'scanned' part will be displayed on a laptop connected to the unit to simulate the scanning process.

\subsection{Survey Instruments}

The effectiveness of the educational module is evaluated by the use of pre and post-module surveys. Table 1 shows the pre and post-survey prompts that are mapped to their corresponding module objectives. The pre-survey is distributed to the student participants before the presentation begins. The students are asked seven questions that test the objectives of the module. At the end of the educational module, the post-survey is distributed to student participants. The post-survey is designed to determine if a significant and favorable change in the responses can be detected. 
Table 1: Pre and Post-Module Survey Map

\begin{tabular}{|c|c|c|}
\hline Objective & Pre-Module Survey Prompts & Post-Module Survey Prompts \\
\hline \multirow{2}{*}{$\begin{array}{c}\text { (1) } \\
\text { Presentation of } \\
\text { Current } \\
\text { Manufacturing } \\
\text { Workforce } \\
\text { Crisis }\end{array}$} & $\begin{array}{l}\text { Manufacturing is an important industry for } \\
\text { the technological prominence of the USA }\end{array}$ & $\begin{array}{c}\text { The USA is in need of more manufacturing } \\
\text { professionals }\end{array}$ \\
\hline & $\begin{array}{l}\text { Manufacturing at a small scale is } \\
\text { important to advancing technology }\end{array}$ & $\begin{array}{l}\text { I think manufacturing especially at a small scale is } \\
\text { important to pushing technology }\end{array}$ \\
\hline \multirow{3}{*}{$\begin{array}{c}\text { (2) } \\
\text { Inspire } \\
\text { Student } \\
\text { Interest in } \\
\text { Manufacturing }\end{array}$} & $\begin{array}{l}\text { The field of manufacturing is of interest to } \\
\text { me }\end{array}$ & $\begin{array}{c}\text { My interest in manufacturing and manufacturing } \\
\text { engineering has increased as a result of this } \\
\text { presentation }\end{array}$ \\
\hline & $\begin{array}{l}\text { I would like to take courses that teach me } \\
\text { about manufacturing }\end{array}$ & $\begin{array}{l}\text { My interest in manufacturing and manufacturing } \\
\text { engineering has increased as a result of this } \\
\text { presentation }\end{array}$ \\
\hline & $\begin{array}{l}\text { I think I would enjoy a career in } \\
\text { manufacturing }\end{array}$ & $\begin{array}{c}\text { My interest in manufacturing and manufacturing } \\
\text { engineering has increased as a result of this } \\
\text { presentation }\end{array}$ \\
\hline \multirow{2}{*}{$\begin{array}{c}\text { (3) } \\
\text { Introducing } \\
\text { Additive \& } \\
\text { Subtractive } \\
\text { Manufacturing } \\
\text { Concepts }\end{array}$} & $\begin{array}{l}\text { I understand what additive manufacturing } \\
\text { is }\end{array}$ & I understand what additive manufacturing is \\
\hline & $\begin{array}{l}\text { I understand what subtractive } \\
\text { manufacturing is }\end{array}$ & I understand what subtractive manufacturing is \\
\hline
\end{tabular}




\section{Preliminary Results}

The above outreach module has been showcased at four local high-school events. In April 2012, the module was first presented at a local high school to two classes of students ranging in age from 14 to 17. During the following month, the Additive Manufacturing mMT and the Interactive Presentation were displayed at the 2012 STEM \& Career Pathways Expo. At this particular event, students, teachers, and parents of all ages visited the display (Figure 18) and asked questions about the Lego ${ }^{\mathrm{TM}}$-based machine and presentation material. During the summer of 2012, the educational module was put on display for middle school aged students at a special event for minority students at Rensselaer Polytechnic Institute. The use during this time was much more formal than a classroom visit, but proved that the module is adaptable to multiple venues and presentation styles. In October 2012, the module was presented in its entirety during the National Manufacturing Day activities at Rensselaer Polytechnic Institute.

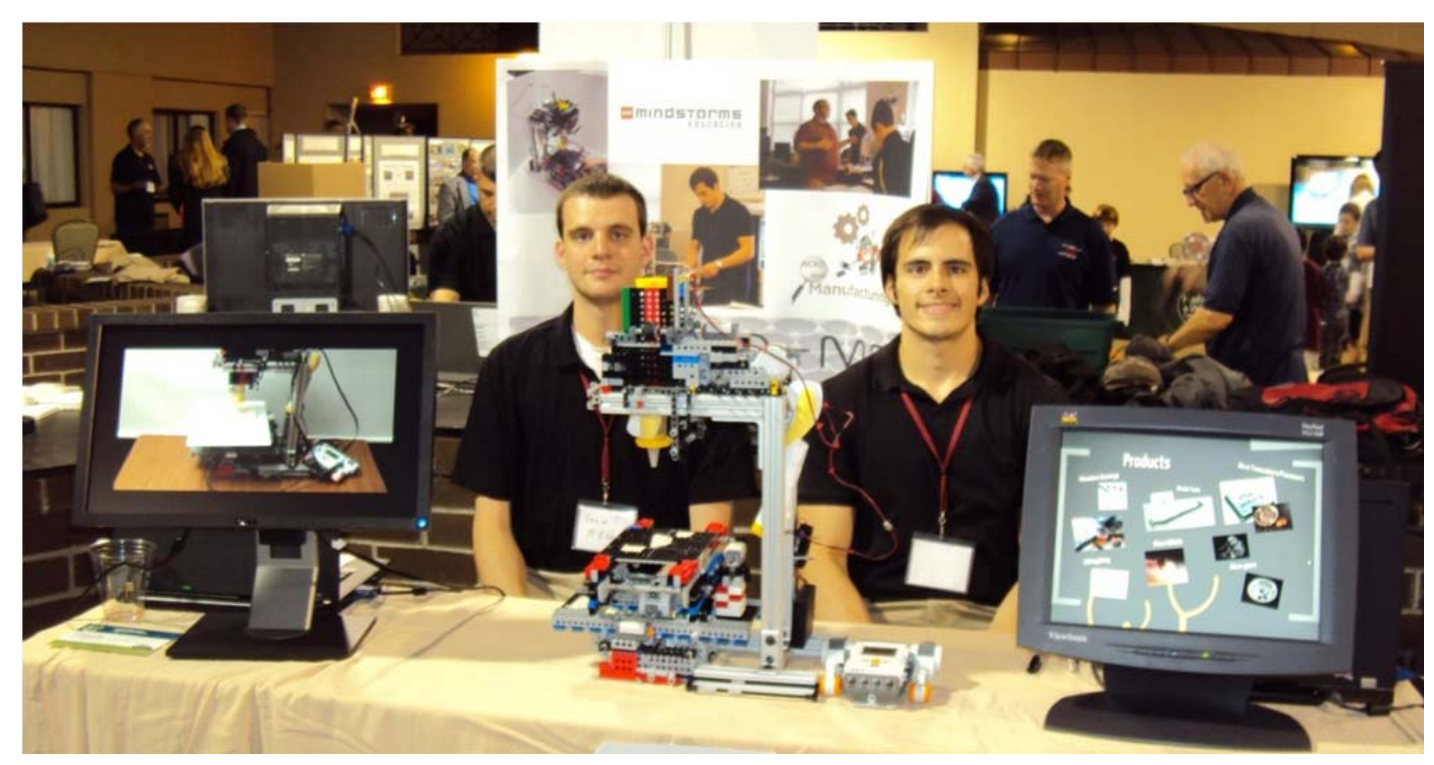

Figure 21: Table Display at 2012 STEM \& Career Pathways Expo

A couple of observations were made from these four events:

1) Students are excited when they see the Lego-based Micro-scale Machine Tool;

2) Legos ${ }^{\mathrm{TM}}$ help bridge the gap between something they are familiar with and modern technology; and

3) The videos and the active presentation hold the attention of the viewers and gets them excited about manufacturing.

Preliminary use of the previously described pre and post-module surveys revealed that

1) Objective 3 of introducing additive and subtractive manufacturing concepts is being met. Statistics show that there is a significant improvement in the knowledge of manufacturing processes after the educational module. 
2) Objective 1 that deals with presenting the current manufacturing workforce crisis is being partially met. Either students are well aware of the current manufacturing workforce crisis, or this fact is not conveyed well enough during the educational module. It is likely that the latter statement is true. Currently, the educational module is aimed more toward sparking an interest with students rather than focusing on the American manufacturing crisis.

3) Objective 2 that deals with inspiring the students requires the most improvement. Statistically, there is not a significant change in the students' interest in manufacturing after the educational module. This may be the most difficult objective to tackle as many students that we encountered have their sights already set on other career paths. While it is difficult to change the perception of students within the one-hour time allotment of our preliminary studies, further uses of the module could be integrated with day or week long events in order to have a more profound and prolonged impact.

Collection of a large sample of survey responses is required to make stronger conclusions about the effectiveness of the outreach module. However, based on the above preliminary findings, the following improvements are being currently pursued:

1) Convey the current manufacturing crisis in the US as part of the presentation.

2) Build the subtractive manufacturing mMT and metrology unit. The addition of these mMTs may improve the module's ability to inspire students to pursue careers in manufacturing or manufacturing engineering.

3) Share current opportunities in this field and problems that will need to be solved in the near future. In doing so, students may find inspiration to pursue manufacturing careers.

\section{Conclusion}

In response to the manufacturing workforce crisis facing the nation, the authors have developed a micro/nano-scale manufacturing educational outreach module designed to inspire K-12 students to pursue careers in manufacturing. Current work of this module can be summed up as follows:

1) An interactive presentation highlighting the micro/nano-scale manufacturing processes, and the state of manufacturing in the United States was developed.

2) Three Lego-based Micro-scale Machine Tools have been designed to demonstrate additive manufacturing, subtractive manufacturing, and metrology processes. Currently, the additive manufacturing Micro-scale Machine Tool has been built.

3) Survey Instruments were created to evaluate the effectiveness of the educational outreach module in reaching its goals.

4) Preliminary results from four separate interactions with K-12 students revealed the areas of improvement and reassurance that Legos are effective in connecting to K-12 students.

5) The preliminary results identified the following next steps: 
- Implement the build from design of the Subtractive Manufacturing Micro-scale Machine Tool and the Metrology Unit.

- Modify content to address the weaknesses found form the preliminary use of the survey instrument.

- Large scale testing of effectiveness of the micro/nano-scale manufacturing educational outreach module.

\section{Acknowledgement}

The authors gratefully acknowledge support from the US National Science Foundation (NSF). The contents of this paper were a result of the outreach activities conducted under the NSF award number CMMI 11-30215. The authors also acknowledge Jordan Vener from the Rensselaer Center for Initiatives in Pre-college Education (CIPCE) for providing the infrastructure support needed to build the Lego test-beds. Elizabeth Herkenham from the Resselaer Engineering Ambassadors program is acknowledged for her critical feedback during the early stages of the module development and for providing us the opportunities to participate in their high-school outreach programs.

\section{Bibliography}

1. K. L. Devine, C. Zimmerman, "A Low-Cost Manufacturing Outreach Activity for Elementary School Students," in Proceedings of the 2012 ASEE Annual Conference, San Antonio, TX, June 2012, Session 5376.

2. L. Chen, D. Kim, H. Gurocak, "Outreach Program with Summer Camps and Manufacturing Engineering Workshops," in Proceedings of the 2005 ASEE Annual Conference, Portland, OR, June 2005, Session 3563.

3. H. Jack, "Increasing Manufacturing Engineering Enrollment Through K-12 Outreach," in Proceedings of the 2004 ASEE Annual Conference, Salt Lake City, UT, Session 2563.

4. J. P. Coulter, H. F. Nied, C. R. Smith, D. C. Angstadt, "Involving Middle School Students in Customer Focused Undergraduate Manufacturing Education," in Proceedings of the 2003 ASEE annual Conference, Nashville, TN, Session 2560.

5. K.F. Ehmann, D. Bourell, M.L. Culpepper, T.J. Hodgson, Th.R. Kurfess, M. Madou, K. Rajurkar, and R.E. DeVor, 2007, Micromanufacturing: International research and development. Springer, New York, NY.

6. "Unwavering Commitment: The Public's View of the Manufacturing Industry Today", 2011, Report sponsored by Deloitte and The Manufacturing Institute.

7. J. Samuel, R.E. DeVor, S.G. Kapoor, and J. Hsia, 2006, "Experimental Investigation of the Machinability of Polycarbonate Reinforced with Multiwalled Carbon Nanotubes", ASME Journal of Manufacturing Science and Engineering, 128, pp. 465-473.

8. J-U Park, M. Hardy, S.J. Kang, K. Barton, K. Adair, D.K. Mukhopadhyay,C.Y. Lee, M.S. Strano, A.G. Alleyne, J.G. Georgiadis, P.M. Ferreira, and J.A. Rogers, 2007, "High-resolution electrohydrodynamic jet printing", Nature Materials, 6, pp. 782-789.

9. S. Mishra, K. Barton, A. Alleyne, P. Ferreira, P., and J. Rogers, 2010, "High speed drop-on-demand printing with a pulsed electro-hydrodynamic jet", Journal of Micromechanics and Microengineering, 20 (9), pp. 0950261-8. 
10. X. Liu, R.E. DeVor, S.G. Kapoor, and K.F. Ehmann, 2004, "The mechanics of machining at the microScale: Assessment of the current state of the science", ASME Journal of Manufacturing Science and Engineering, 126(4), pp. 666-678.

11. I. Ghai,J.E. Wentz, S.G. Kapoor, R.E. DeVor, and J. Samuel, J., 2009 "Droplet Behavior on a Rotating Surface for Atomization-based Cutting Fluid Application in Micro-machining", ASME Journal of Manufacturing Science and Engineering, 132(1), pp. 011017 (10 pages).

12. L. Sun, S. T. Parker, D. Syoji, X. Wang, J. A. Lewis, and D. L. Kaplan, "Direct-Write Assembly of 3D Silk/Hydroxyapatite Scaffolds for Bone Co-Cultures," Advanced Healthcare Materials, vol. 729-735, no. 1, May. 2012. 